\title{
GESTÃO DE RESTOS A PAGAR: ESTUDO DE CASO DOS RESULTADOS ALCANÇADOS PELA UFSC NO PERÍODO DE 2011 A 2016
}

\author{
MANAGEMENT OF DEBITS REMAINS TO PAY: CASE STUDY OF RESULTS \\ ACHIEVED BY UFSC IN THE PERIOD FROM 2011 TO 2016
}

\author{
GABRIEL NILSON COELHO \\ Universidade Federal de Santa Catarina. Endereço: Av. Desembargador Vitor \\ Lima $n^{\circ} 222$, Prédio II da Reitoria $6^{\circ}$ andar, sala 602 | Trindade | 88040-400| \\ Florianópolis/SC | Brasil. \\ (D)http://orcid.org/0000-0002-5558-079X \\ gn.coelho@hotmail.com
}

\section{GUILHERME MARTINS SANTANA}

Universidade Federal de Santa Catarina. Endereço: Av. Desembargador Vitor Lima $n^{\circ} 222$, Prédio II da Reitoria $6^{\circ}$ andar, sala 602 | Trindade | 88040-400| Florianópolis/SC $\mid$ Brasil.

Dhttp://orcid.org/0000-0003-0614-7057

g.santana@ufsc.br

\section{VLADIMIR ARTHUR FEY}

Universidade Federal de Santa Catarina. Endereço: Av. Desembargador Vitor Lima $n^{\circ} 222$, Prédio II da Reitoria $6^{\circ}$ andar, sala 602 | Trindade | 88040-400| Florianópolis/SC | Brasil.

(1D http://orcid.org/0000-0001-5297-9044

vladimir.arthur@ufsc.br

\section{EDICREIA ANDRADE DOS SANTOS}

Universidade Federal de Mato Grosso do Sul. Escola de Administração e Negócios. Endereço: Av. Sen. Filinto Müler, 1015 | Cidade Universitária | 79046-460 | Campo Grande/MS | Brasil.

(D) http://orcid.org/0000-0001-8745-3579

edicreiaandrade@yahoo.com.br

\section{RESUMO}

Este estudo buscou verificar os reflexos das ações efetuadas por uma instituição pública de ensino superior na gestão dos restos a pagar (RP) no período de 2011 a 2016, tendo como base sua composição, evolução, as ações efetuadas pelos gestores e os resultados alcançados. Para tal, foi realizado um estudo de caso com dados obtidos junto aos sites de órgãos de controle e fiscalização, informações do sistema SIAFI e dos Relatórios de Gestão. A análise do montante total empenhado e inscrito do período permitiu verificar que as despesas de capital apresentaram taxas elevadas de inscrição em RP. Das despesas que compõem o montante de restos a pagar não processados (RPNP), observou-se que uma parcela representativa das despesas é decorrente da prestação de 
serviços por pessoas jurídicas, especificamente de despesas essenciais para o funcionamento da universidade. A evolução das inscrições em RPNP referente a natureza de despesa mais representativa na composição, juntamente com a correlação das ações dos departamentos responsáveis na gestão de RP, evidenciaram que uma maior interação com os fiscais de contrato, a realização de treinamentos para ordenadores de despesas e a implementação de procedimentos específicos culminaram em uma queda na inscrição de RPNP e, por conseguinte, em RP.

Palavras-chave: Restos a Pagar. Despesas Orçamentárias. Instituição de Ensino.

\begin{abstract}
This study sought the results of the actions carried out by a public higher education institution according to the year 2011 in 2016, based on its composition, evolution, the actions performed by the managers, and the results achieved. For that, a case study was carried out with inspection of data with the control and inspection bodies, information about the SIAFI system and the Management Reports. Doses were examined in the analysis of the total amount committed and registered during the period that the capital expenses were paid in RP. The expenses that make the payment of reimbursement to benefits paid (RPNP) noted that the representativeness of expenses was conditioned by the provision of services by legal entities, specifically functions essential to the functioning of the university. The creation of RPNP registrations referred to a more representative nature of remuneration in composition, together with the actions of the departments responsible for remuneration management, the disclosure of a greater interaction with the study contract, the performance of training for computers of expenses and Implementation of specific procedures.
\end{abstract}

Keywords: Remains to Pay. Budgetary Expenditures. Institution of Education.

\title{
1 INTRODUÇÃO
}

A Lei 4.320/64, no caput do art. 36, limita a data de 31 de dezembro de cada ano como prazo máximo para que o Estado cumpra com seus pagamentos decorrentes das obrigações assumidas com terceiros; do contrário, deverá o responsável pelos lançamentos das contas públicas registrar, nas peças contábeis, como restos a pagar, conforme art. 34 da referida Lei. A inscrição dos restos a pagar, no fim do exercício, reconhece como despesa um fato que ainda vai ocorrer, são despesas empenhadas, mas não pagas até o último dia do ano financeiro, podendo ser segregadas em duas categorias: processadas e não processadas (MCASP, 2017).

A respeito das despesas processadas, Kohama (2010) aponta que são aquelas cujo empenho foi apresentado ao credor, este por sua vez entregou o material ou forneceu o serviço e a despesa foi liquidada, encontrando-se na etapa do pagamento. As despesas não processadas são aquelas cujo empenho foi emitido, contudo, o objeto adquirido ainda não foi entregue e depende de algum fator para a efetiva liquidação (Kohama, 2010).

Na literatura acadêmica, o instrumento Restos a Pagar é criticado por diferentes autores e sob distintos aspectos: (i) por possibilitar um acúmulo de dívidas para a entidade pública, e, por consequência, dificuldades financeiras para a gestão no exercício seguinte (Neres, 2010); (ii) por apresentar um resultado patrimonial inapropriado, desrespeitando assim o princípio da competência (Piscitelli \& Timbó, 2010); (iii) pelo fato de seus procedimentos serem efetuados de modo apressado, haja vista o interesse de que os recursos não sejam perdidos (Alves, 2011); e (iv) por apresentar divergências entre a execução orçamentária e a financeira (Giacomoni, 2012).

$\mathrm{Na}$ esfera legal, a Lei da Responsabilidade Fiscal (LRF) e o Decreto $\mathrm{n}^{\circ}$ 93.872/86 procuram restringir a existência de restos a pagar nos orçamentos públicos, cancelando aqueles que não cumprem o disposto em seus artigos e até mesmo punindo gestores por crimes de responsabilidade. 
Por meio de auditorias, a Controladoria Geral da União (CGU) acompanha as Unidades Gestoras com o intuito de orientá-las quanto a adoção de controles necessários dos saldos em restos a pagar.

Aquino e Azevedo (2015) argumentam que a boa posição do Brasil nos índices Public Expenditure and Financial Accountability (Pefa) e Open Budget Initiative (OBI) deve ser vista com cautela. Apesar da nota máxima na divulgação do RPP para o governo federal no índice Pefa, e a LRF ser elogiada por regular a questão de forma ampla, os autores destacam que as medidas se aplicam aos RPP, e nada é dito sobre o RPNP, que tem disparado na última década, talvez por não ter sido alvo de qualquer regulação.

Nessa linha, com o objetivo de maior controle dos saldos em restos a pagar, as instituições públicas devem estabelecer rotinas e procedimentos administrativos de forma a garantir a efetivação de ações voltadas ao uso adequado e eficiente do Instrumento Restos a Pagar (Peixoto $\&$ Peixoto 2017). Sob este entendimento, com vistas a entender os reflexos dessas ações em uma instituição pública de ensino superior, apresenta-se a seguinte questão de pesquisa: Qual o reflexo das ações efetuadas pela Universidade Federal de Santa Catarina (UFSC) na gestão dos restos a pagar no período de 2011 a 2016? Assim, tem-se como objetivo analisar o reflexo das ações efetuadas pela UFSC na gestão dos restos a pagar no período de 2011 a 2016, tendo como base a composição dos restos a pagar, sua evolução no período proposto correlacionado com as ações efetuadas pelos gestores competentes e os resultados alcançados.

A justificativa deste estudo ampara-se no papel que a contabilidade pública tem, de gerar informações econômicas, financeiras, orçamentárias e patrimoniais, e com isso possibilitar maior transparência na sociedade a respeito de como os recursos públicos estão sendo obtidos e aplicados. Nesta direção, o intuito de analisar a inscrição de restos a pagar não processados devese à relevância que essa prática tem no comprometimento da execução financeira do orçamento do exercício subsequente, bem como torná-la tópico de discussão face ao momento de contingenciamento de recursos públicos federais. Quanto às características orçamentárias, a UFSC apresentou nos exercícios analisados valores anuais superiores a 900 milhões de reais como dotação inicial, configurando-se como um dos maiores orçamentos públicos no estado de Santa Catarina. Portanto, espera-se que este estudo possibilite, a partir da realidade da UFSC, uma melhor compreensão acerca de ações ligadas à gestão de restos a pagar.

\section{FUNDAMENTAÇÃO TEÓRICA}

\subsection{Etapas da despesa orçamentária e formação de restos a pagar}

Conforme o MCASP (2017), em sua sétima edição, a etapa da execução da despesa é precedida por: (i) planejamento, etapa que abrange toda a análise para a formulação do plano e ações governamentais que servirão de base para a fixação da despesa orçamentária; (ii) descentralização ou movimentação de créditos; (iii) programação orçamentária e financeira; e (iv) processo de licitação e contratação. Por sua vez, a execução da despesa orçamentária se dá em três estágios: empenho, liquidação e pagamento. A Figura 1 apresenta de forma resumida um fluxograma com as principais fases da etapa de execução, bem como indica o momento em que ocorrem as inscrições em restos a pagar processados e não processados. 


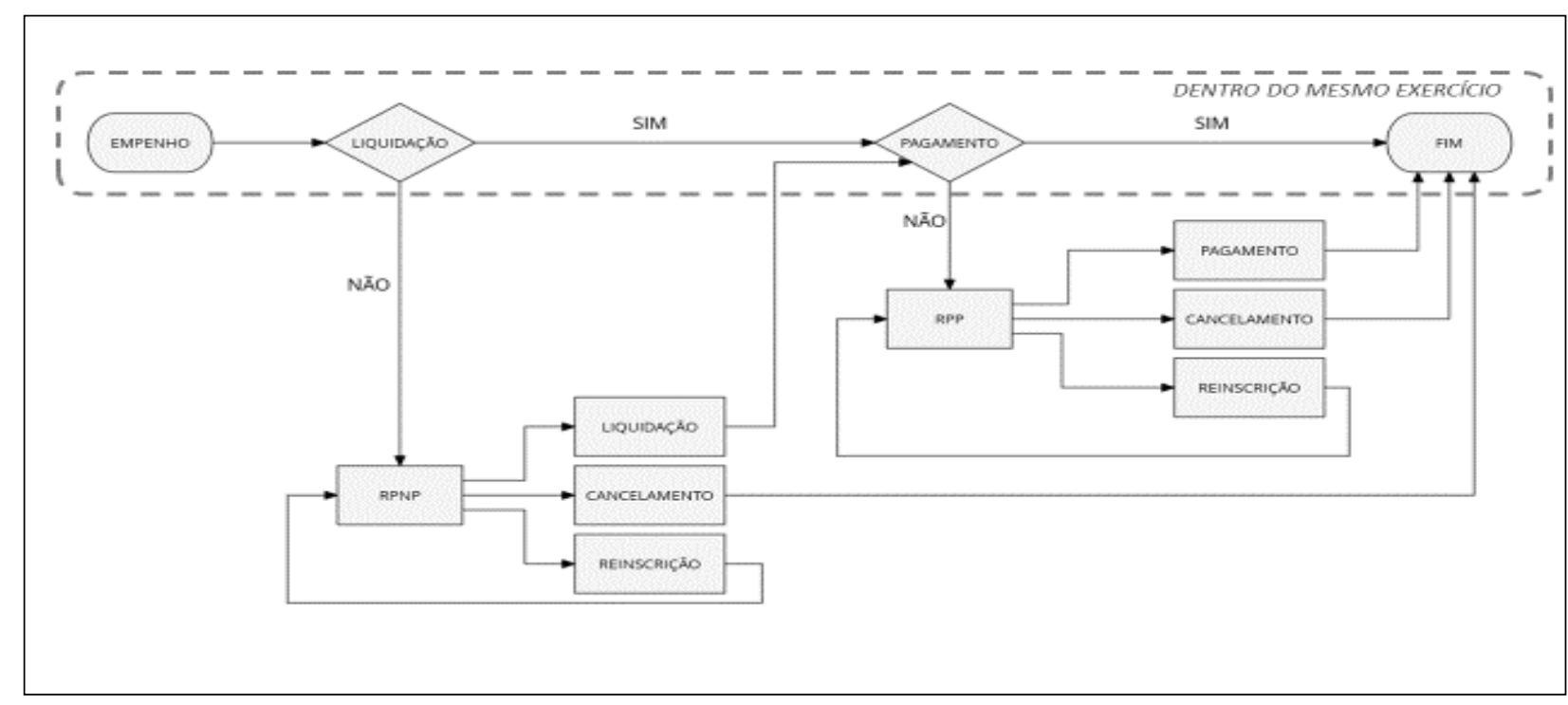

Figura 1. Resumo das etapas da execução da despesa Fonte: Elaborado pelos autores (2018).

Ressalta-se que o fluxograma apresentado na Figura 1 não evidencia todas as especificidades da etapa da execução orçamentária, mas ilustra a sequência de eventos para inscrição em restos a pagar. Isto posto, a seguir discorre-se acerca dos principais conceitos apresentados na Figura 1 conforme legislação pertinente, iniciando-se pelo empenho.

O empenho, conforme art. 58 da Lei $\mathrm{n}^{\circ} 4.320 / 1964$, é o ato emanado de autoridade competente que cria para o Estado obrigação de pagamento pendente ou não de implemento de condição. Sua formalização ocorre com a emissão da nota de empenho, e somente a partir deste momento o crédito empenhado torna-se indisponível para nova aplicação (Lima \& Castro, 2013). Ainda de acordo com estes autores, o empenho representa uma garantia para o fornecedor ou para o prestador de serviço contratado pela administração pública de que a parcela referente ao seu contrato foi bloqueada para honrar os compromissos assumidos; portanto, o orçamento é comprometido através do empenho. Giacomoni (2012) afirma que o período do empenho não configura, de maneira adequada, a competência do exercício, que é caracterizada na realização efetiva da despesa.

Ainda a respeito do empenho, Garcia, Melo, Resende, Neto e Marciniuk (2015) argumentam que o empenho não representa uma obrigação líquida e certa, mas sim que a futura despesa está adstrita ao limite do crédito orçamentário disponível. Os autores destacam ainda que por consistir a verificação do direito adquirido pelo contratado, com base nos documentos que comprovem o crédito, a fim de apurar a origem, o objeto, o credor e a importância do que se deve pagar, o estágio da liquidação é o mais representativo do fato gerador da despesa.

O próximo elemento é a liquidação, que consiste na verificação do direito adquirido pelo credor tendo por base os títulos e documentos comprobatórios do respectivo crédito e tem por objetivo apurar: a origem e o objeto do que se deve pagar; a importância exata a pagar; e a quem se deve pagar para extinguir a obrigação (Lei no 4.320/1964, art. 58). Ainda no artigo 58 observa-se que a liquidação da despesa por fornecimentos feitos ou serviços prestados terá por base: o contrato, ajuste ou acordo respectivo; a nota de empenho; os comprovantes da entrega de material ou da prestação efetiva do serviço.

Vale ressaltar que o PCASP (Plano de Contas Aplicado ao Setor Público) incluiu a fase da execução da despesa - "em liquidação", que busca o registro contábil no patrimônio de acordo com a ocorrência do fato gerador, não do empenho. Segundo o MCASP (2017), tal inclusão de fase torna possível o processo de convergência às normas contábeis internacionais, IPSAS, e isso demonstra-se com a desvinculação do reconhecimento do fato gerador da execução orçamentária, empenho ou liquidação da despesa. Portanto, ao final do exercício financeiro, será por meio deste 
estágio que ocorrerá a classificação das despesas inscritas como Restos a Pagar em Processados (cumprimento das obrigações por parte do credor) e Não Processados.

No tocante ao elemento dos restos a pagar processados (RPP), define-se de acordo com MCASP (2017) como sendo as despesas devidamente empenhadas cujo objeto do empenho foi recebido e não pago até 31/12. Segundo Aquino e Azevedo (2017), a inscrição de RPP pode ser oriunda de gastos já liquidados que não tenham sido pagos dentro do exercício, seja por tempo de processamento ou pela data de vencimento do título. Já a inscrição no RPNP viria da necessidade de manter empenhos para execução futura que tenham sofrido atrasos por fatos imprevistos, em serviços não recorrentes que serão finalizados apenas após o fim do exercício.

Salienta-se que diversos são os motivos pelos quais a parcela do orçamento autorizado não são executadas dentro do exercício financeiro previsto. Garcia et al., (2015) apontam algumas causas como: (i) o contingenciamento, que é o mecanismo utilizado para limitação dos gastos do governo federal; (ii) complexidades do processo licitatório; e (iii) excesso de burocracia e ausência de planejamento, que acabam ocasionando um concentrado número de liberações orçamentárias no final do exercício, o que acarreta grandes números de empenhos. Logo, o tempo para a realização efetiva da despesa se torna escasso, restando promover a inscrição de saldos de empenhos não processados em restos a pagar.

Os restos a pagar não processados (RPNP), por sua vez, tem como ocorrência sua inscrição por indicação do ordenador de despesas com base nos documentos passíveis de inscrições em 31/12, isto é, nos saldos dos empenhos (MCASP, 2017). A este respeito, Garcia et al., (2015) afirmam que os gestores devem ter zelo na avaliação dos saldos dos empenhos ao final do período, com vistas a cancelar todos os documentos que não possuem respaldo legal, conforme disposto na Lei 4.320/64, art. 35, II.

O pagamento consiste na entrega de numerário ao credor por meio de cheque nominativo, ordens de pagamentos ou crédito em conta, e só pode ser efetuado após a regular liquidação da despesa (MCASP, 2017). Acerca da ordem de pagamento, a Lei $\mathrm{n}^{\circ} 4.320 / 1964$, no art. 64, define como sendo o despacho exarado por autoridade competente, determinando que a despesa liquidada seja paga. Vale ressaltar ainda que a despesa somente poderá ser paga por tesouraria ou pagadoria regularmente instituída, por estabelecimentos bancários e, em alguns casos, por adiantamento (Slomski, 2013).

O cancelamento de despesas empenhadas e inscritas em restos a pagar deve observar rotinas específicas quanto às informações de natureza patrimonial, orçamentária e controle. Essa rotina terá tratamento específico, conforme o estágio em que a despesa se encontrar, podendo estar pendente de liquidação ("a liquidar" ou "em liquidação") ou liquidado (MCASP, 2017).

Por fim, vale mencionar, conforme o art. 70 do Decreto ${ }^{\circ} 93.872$ (1986), que a dívida passiva relativa a restos a pagar prescreve em cinco anos. Todavia, há casos em que ocorre o que é chamado de prescrição interrompida, que são as despesas cuja inscrição em restos a pagar sofreram cancelamento, mas ainda está vigente o direito do credor, em virtude da liquidação. Dada a baixa contábil dos restos a pagar e até a sua prescrição, as despesas reconhecidas serão pagas, descrevendo-as como "Despesas de Exercícios Anteriores".

Após a descrição das particularidades das etapas da despesa orçamentária e formação de restos a pagar, faz-se interessante a apresentação de alguns estudos nacionais realizados em âmbito universitário.

\subsection{Impacto dos Restos a Pagar na gestão do equilíbrio fiscal}

As duas formas de restos a pagar (processados e não processados) desafiam o regime fiscal. Contudo, a forma de RPNP é particularmente problemática, pois não circula no orçamento regular; o que deveria ser uma exceção se tornou uma regra (Aquino \& Azevedo, 2017).

De acordo com Camargo (2015), a gestão das finanças do governo fica comprometida se a cada ano uma parcela da despesa deixar de ser paga e passa a ser classificada em restos a pagar, com o simples intuito de ampliar as metas fiscais ou realizar controle político. 
Aquino e Azevedo (2017) constataram que além do crescente endividamento, a fraca regulação, sobretudo dos restos a pagar não processados, está reduzindo seriamente a credibilidade e a transparência do orçamento em todos os níveis de governo. Segundo os autores, a atual regulação e o baixo controle do carry-over via restos a pagar têm como efeitos colaterais o aumento do endividamento, a perda do princípio da anualidade e a redução da credibilidade e da transparência orçamentárias. Os autores ressaltam a necessidade de que a administração pública invista no uso de ferramentas que possibilitem o acompanhamento da execução orçamentária com o intuito de auxiliar o gestor do orçamento no alcance da melhoria da gestão dos gastos públicos, evitando assim que o orçamento público seja simplesmente uma "peça de ficção".

Este estudo, a partir da realidade da UFSC, visa propor uma melhor compreensão acerca de como ações ligadas a gestão de restos a pagar podem impactar na redução de inscrição dos mesmos, combatendo assim o desequilíbrio fiscal, conforme apontado na literatura.

\subsection{Estudos anteriores sobre despesas orçamentárias em universidades}

Com o intuito de alargar o entendimento acerca das despesas orçamentárias no âmbito das universidades federais brasileiras, discorre-se a seguir sobre alguns estudos (Magalhães, Oliveira, Wakim \& Faroni, 2006; Neves, Libonati, Miranda \& Menezes, 2014; Silva, Neves, Campos \& Vasconcelos, 2014; Santana, 2016) que enfatizaram diferentes amostras e aspectos. Salienta-se como critério de escolha destes estudos a similitude de aplicação da problemática e do ambiente de pesquisa.

Magalhães et al., (2006) analisaram a evolução orçamentária da Universidade Federal de Viçosa (UFV) no período de três anos (2001-2003). Os resultados evidenciaram que o valor da despesa orçada maior que a despesa executada deveu-se ao contingenciamento de cotas orçamentárias pelo governo federal, não sendo possível gastá-lo naquele período, além de que não houve tempo suficiente para proceder à licitação para aquisição dos bens e serviços necessários à manutenção das atividades diárias da Instituição. Quanto aos restos a pagar de cada elemento de despesas, verificou-se que estes podem ter ocorrido em razão do maior prazo concedido pelos fornecedores nas compras efetuadas pela UFV.

Com vistas a investigar os eventos que afetaram a execução física e orçamentária dos programas "Brasil Universitário" e "Desenvolvimento do Ensino da Pós-Graduação e da Pesquisa Científica", conduzidos pelos gestores das universidades federais brasileiras, Neves et al., (2014) aplicaram o método de análise de conteúdo nas informações dos relatórios de gestão de dezenove universidades, situadas em quatro regiões brasileiras. Dentre os achados, observaram que atrasos na liberação dos recursos, quando oriundos de emendas parlamentares, influenciaram significativamente a execução orçamentária e física das ações. Ademais, concluíram que os investimentos, que correspondem à realização de obras e aquisição de equipamentos, possuem um baixo índice de liquidação e de pagamento no exercício em que ocorre o empenho.

Com o objetivo de verificar se houve modificação na situação dos restos a pagar nas universidades federais da região Nordeste com o advento do decreto $\mathrm{n}^{\circ} 7.654$, de 23 de dezembro de 2011, que aumentou em seis meses o prazo de validade dos restos a pagar não processados e também possibilitou exceções ao cancelamento de determinadas despesas após sua publicação, Silva et al., (2014) analisaram a execução orçamentária em catorze universidades. Os autores observaram que não houve diferenças estatísticas entre o antes e o depois do decreto em relação ao percentual de restos a pagar sobre o montante empenhado pelas instituições.

Santana (2016) estudou o volume total executado do orçamento dos anos de 2011 a 2013 na Universidade Federal de Santa Catarina (UFSC), correlacionando com a execução dos Restos a Pagar inscritos pela instituição. Analisando os dados orçamentários, verificou que o volume de inscrição de Restos a Pagar se manteve acima de 50\% do valor originalmente empenhado nos três exercícios analisados. Destacou a dificuldade na execução de obras por parte da instituição, assim como nas demais despesas de capital, já que apresentaram inscrição em Restos a Pagar acima da média e maior índice de cancelamento. 
Face à descrição dos estudos apresentados, verifica-se a existência de pesquisas acerca da problemática da inscrição de restos a pagar no âmbito das universidades públicas. Contudo, percebe-se também a necessidade de estudos que abordem a questão de ações adotadas pelas instituições na área da gestão de restos a pagar e resultados obtidos.

\section{PROCEDIMENTOS METODOLÓGICOS}

Este estudo de caráter descritivo com abordagem qualitativa foi realizado por meio de estudo de caso, junto a uma instituição de ensino superior pública e federal - a Universidade Federal de Santa Catarina (UFSC). Em relação à abordagem, enfatiza-se que embora instrumentos estatísticos simples tenham sido empregados no processo de análise e interpretação dos dados, a intenção é descrever e compreender as peculiaridades e dinamismo da gestão de Restos a Pagar.

\subsection{Coleta e tratamento de dados}

A coleta de dados deu-se, em parte, on-line junto ao Portal da Transparência e sítios eletrônicos de órgãos de controle e fiscalização, e por meio do sistema SIAFI Gerencial (plataforma que disponibiliza serviços de consulta, consulta construída e geração de relatórios para o Balanço Geral da União, baseando-se nas informações de execução orçamentária, financeira e patrimonial registradas). Enfatiza-se, para fins de validade da pesquisa, que, por se tratar de uma instituição pública, a Lei $\mathrm{n}^{\circ} 12.527 / 11$ (Lei de Acesso à Informação), garante acesso às informações públicas mediante solicitação.

Ressalta-se que se obteve acesso aos Relatórios de Gestão dos anos analisados (2011 a 2016), para possibilitar a avaliação em conjunto com os dados quantitativos, as reincidências ou não de apontamentos sobre Restos a Pagar nos relatórios de auditoria, e indicativos de possíveis alterações nos procedimentos relativos aos Restos a Pagar no período analisado. Por conseguinte, a partir da compilação e tratamento dos dados coletados elaborou-se, com uso de ferramentas como o Excel, tabelas e gráficos com o intuito de facilitar as interpretações e análises propostas. Deste modo, as extrações de dados realizadas via sistemas SIAFI Gerencial classificam-se, neste processo de coleta, como fontes de primeira mão, haja vista que não sofreram nenhum tratamento analítico anterior; já os Relatórios de Gestão, por terem passado por análise prévia, como fontes de segunda mão (Gil, 1999).

\subsection{Delimitação da pesquisa}

Este estudo tem como foco a análise dos restos a pagar da UFSC, no período de 2011 a 2016. Justifica-se a escolha desses seis anos por possibilitar uma análise e comparação de valores de forma mais ampla, permitindo identificar como realmente evoluíram os restos a pagar, qual sua composição, quais as inscrições mais significativas por classificação, qual o montante inscrito a cada ano e quais os impactos das ações dos gestores na evolução ao longo dos anos. Vale ressaltar que o ano de 2017 não foi incluído na análise pelo fato de a contabilização do exercício não estar finalizada quando da elaboração desta pesquisa.

A UFSC tem como sede o munícipio de Florianópolis (Santa Catarina), é uma autarquia de regime especial vinculada ao Ministério da Educação (MEC). Foi criada no ano 1960 por meio da Lei $\mathrm{n}^{\mathrm{o}} 3.849$ e abriga uma comunidade estimada em 50 mil pessoas, entre discentes e servidores (por exemplo: docentes e técnicos administrativos). Quantos às características orçamentárias, a UFSC (Unidade Gestora 153163) apresentou nos exercícios analisados valores anuais superiores a 900 milhões de reais como dotação inicial, configurando-se como um dos maiores orçamentos públicos no estado de Santa Catarina. 


\section{ANÁLISE DOS DADOS E DISCUSSÃO DOS RESULTADOS}

A análise exposta nesta seção diz respeito às despesas discricionárias, não fazendo parte da análise as despesas de pessoal, visto que possuem uma maior facilidade para execução, em parte por não serem regidas pela Lei de Licitações (Lei no 8.666/93) para sua realização, e também pelo fato dos créditos orçamentários serem autorizados com base em valores previamente estabelecidos. Portanto, despesas obrigatórias, aquelas que não dependem da ação do gestor para ocorrerem, possuindo caráter obrigatório quanto ao seu pagamento, também estão excluídas da análise.

As tabelas e gráficos apresentados estão na escala de milhar (x1000), para uma melhor evidenciação dos valores e saldos. Siglas foram utilizadas na elaboração das tabelas e gráficos, bem como na análise efetuada, tais como: Restos a Pagar (RP), Restos a Pagar Processados (RPP), Restos a Pagar Não processados (RPNP). Por fim, salienta-se que a análise contempla apenas a inscrição em restos a pagar dos períodos, estando assim excluídos dos saldos e movimentações apresentadas as reinscrições, cancelamentos e pagamentos.

O primeiro subtópico apresenta a composição dos restos a pagar do período investigado, apresentando as classificações previstas em lei e evidenciando com maior detalhamento as despesas mais significativas da composição. O segundo subtópico analisa a evolução das inscrições, apresentando as "relações causa-efeito" das ações efetuadas pela administração na instituição na gestão dos restos a pagar.

\subsection{Composição dos Restos a Pagar inscritos no período de 2011 a 2016}

A Lei $\mathrm{n}^{\circ}$ 4.320/64 classifica as despesas correntes como sendo as (i) despesas de custeio (encargos salariais, aquisição de materiais etc.), e as (ii) transferências correntes (encargos com inativos e pensionistas, juros da dívida ativa etc.). As despesas de capital, segundo a referida Lei, compreendem os investimentos, inversões financeiras e transferências de capital. Neste entendimento, a Tabela 1 faz uso desta classificação para destacar os valores empenhados e inscritos em restos a pagar no período de 2011 a 2016, evidenciando os percentuais correspondentes de valores inscritos.

Tabela 1

Relação dos valores empenhados e inscritos em Restos a Pagar no período de 2011 a 2016

\begin{tabular}{cccccccccc}
\hline Ano & \multicolumn{3}{c}{ Corrente } & \multicolumn{3}{c}{ Capital } & \multicolumn{3}{c}{ Total } \\
\cline { 2 - 10 } & $\mathbf{E M P}$ & $\mathbf{R P}$ & $\mathbf{\%}$ & $\mathbf{E M P}$ & $\mathbf{R P}$ & $\mathbf{\%}$ & $\mathbf{E M P}$ & $\mathbf{R P}$ & $\mathbf{\%}$ \\
& $\mathbf{( 1 )}$ & $\mathbf{( 2 )}$ & $\mathbf{( 2 / 1 )}$ & $\mathbf{( 3 )}$ & $\mathbf{( 4 )}$ & $\mathbf{( 3 / 4 )}$ & & $\frac{(\mathbf{1 + 3})}{(\mathbf{2 + 4})}$ \\
\hline $\mathbf{2 0 1 1}$ & 198.126 & 80.431 & $40,60 \%$ & 70.157 & 57.518 & $81,98 \%$ & 268.284 & 137.949 & $51,42 \%$ \\
$\mathbf{2 0 1 2}$ & 269.376 & 131.177 & $48,70 \%$ & 83.610 & 48.475 & $57,98 \%$ & 352.986 & 179.652 & $50,90 \%$ \\
$\mathbf{2 0 1 3}$ & 302.878 & 136.794 & $45,16 \%$ & 86.953 & 65.060 & $74,82 \%$ & 389.831 & 201.854 & $51,78 \%$ \\
$\mathbf{2 0 1 4}$ & 257.586 & 84.158 & $32,67 \%$ & 43.648 & 34.992 & $80,17 \%$ & 301.234 & 119.150 & $39,55 \%$ \\
$\mathbf{2 0 1 5}$ & 219.756 & 57.967 & $26,38 \%$ & 42.760 & 36.540 & $85,45 \%$ & 262.516 & 94.507 & $36,00 \%$ \\
$\mathbf{2 0 1 6}$ & 299.308 & 70.757 & $23,64 \%$ & 39.981 & 26.297 & $65,77 \%$ & 339.289 & 97.054 & $28,61 \%$ \\
Total & 1.547 .030 & 561.284 & $36,28 \%$ & 367.109 & 268.882 & $73,24 \%$ & 1.914 .140 & 830.166 & $43,37 \%$ \\
\hline
\end{tabular}

Nota. EMP: Empenho; RP: Restos a Pagar

Fonte: Dados da pesquisa (2018).

Conforme dados apresentados na Tabela 1 é possível verificar um alto índice de inscrição de empenhos referentes a despesas de capital, com percentuais de inscrição acima de $50 \%$ ao final de cada ano analisado, atingindo taxas acima de $80 \%$ em 4 dos 7 anos analisados. Como as despesas de capital estão ligadas aos gastos com investimentos, como obras e compra de material permanente, essas despesas tendem a ter um processo de execução mais complexo e com prazos mais dilatados, e podem estar mais sujeitas a atrasos ou mesmo descontinuidade por problemas contratuais ou fatores econômicos. Esse é um bom caso para um estudo futuro em relação à execução orçamentária das despesas de capitais. 
As despesas correntes apresentam percentuais que variam de 23,64\% (2016) a 48,7\% (2012), bem abaixo dos registrados pelas despesas de capital. Destaca-se a diminuição no percentual de RP inscritos ao longo do período, sendo que nos três primeiros anos analisados (2011, 2012 e 2013), os dados indicam que para cada $R \$ 2,00$ empenhados, pelo menos $R \$ 1,00$ se convertia em uma despesa planejada, porém não executada, sendo assim inscrita em restos a pagar. A partir do ano de 2014 o percentual de restos a pagar inscritos tem uma queda na sua proporção frente aos empenhos realizados, alcançando a taxa mais baixa $(28,61 \%)$ no ano de 2016 . A análise das causas dessas variações é abordada no próximo subtópico. No que diz respeito à composição do RP do período, verifica-se um predomínio das despesas correntes, que somam um total de $\mathrm{R} \$ 561.284,00$ e representam $80,82 \%$ das inscrições realizadas.

O montante total inscrito em restos a pagar no período analisado é apresentado na Tabela 2, que segrega os Restos a Pagar em: Restos a Pagar Processados (RPP) e Restos a Pagar Não Processados (RPNP). Os processados representam as despesas liquidadas, aquelas em que o bem ou o serviço correspondente já foi entregue. Por sua vez, os não processados passaram apenas pelo estágio do empenho e não foram liquidados.

Tabela 2

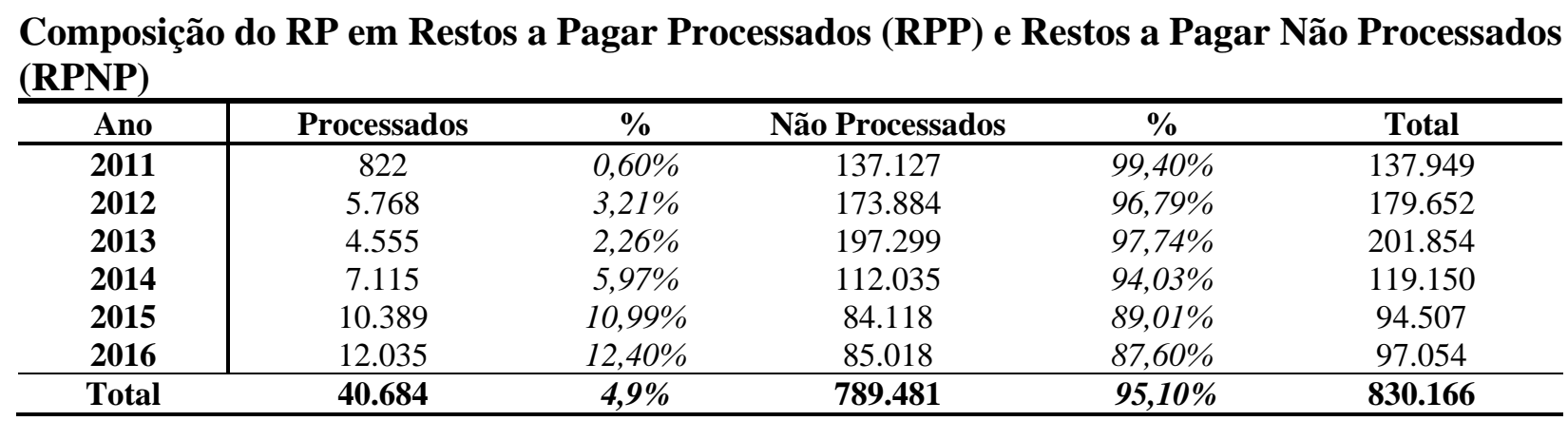

Fonte: Dados da pesquisa (2018).

Os dados permitem verificar que cerca de $90 \%$ dos valores inscritos em Restos a Pagar é Não Processado. Os Restos a Pagar Não Processados carregam para o próximo exercício uma dotação que, embora vinculada, não é comprometida, pois a despesa correspondente ainda carece da liquidação (também denominada de Restos a Fazer). A proporção de RPNP face ao total inscrito diminuiu ao longo dos anos, tendo como ápice o ano 2011 com 99,4\% do valor inscrito, caindo para 87,6\% no ano de 2016. O aumento dos RPP representa que ao longo dos anos mais despesas foram liquidadas no ano em que foram empenhadas, sendo transferida para o ano seguinte apenas a obrigação financeira.

Haja vista a representatividade dos RPNP no período analisado, cabe uma averiguação das naturezas de despesa que compõe os $95,10 \%$ das inscrições em restos a pagar no período de 2011 a 2016 (R\$ 789.481.267,83). A Figura 2 apresenta a proporção por natureza de despesa das inscrições efetuadas em RPNP no período analisado. 


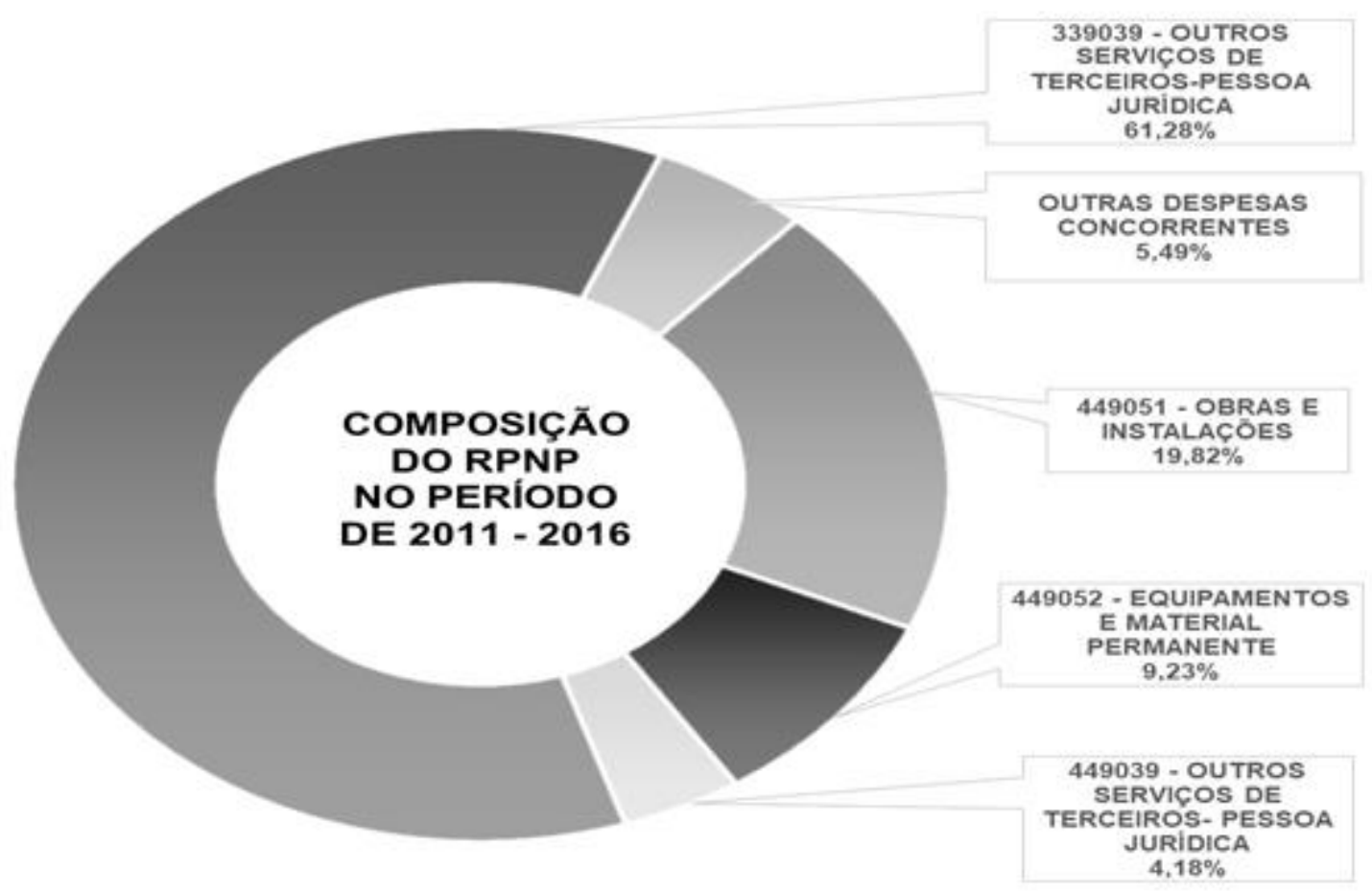

Figura 2. Composição dos Restos a Pagar Não Processados (RPNP) no período Fonte: Dados da pesquisa (2018).

Complementarmente à Figura 2, apresenta-se a Tabela 3, a qual evidencia o montante anual inscrito em cada natureza de despesa apresentada e o percentual correspondente relativo ao valor inscrito total anual.

Tabela 3

Composição do RPNP segregada por natureza de despesa e ano de inscrição

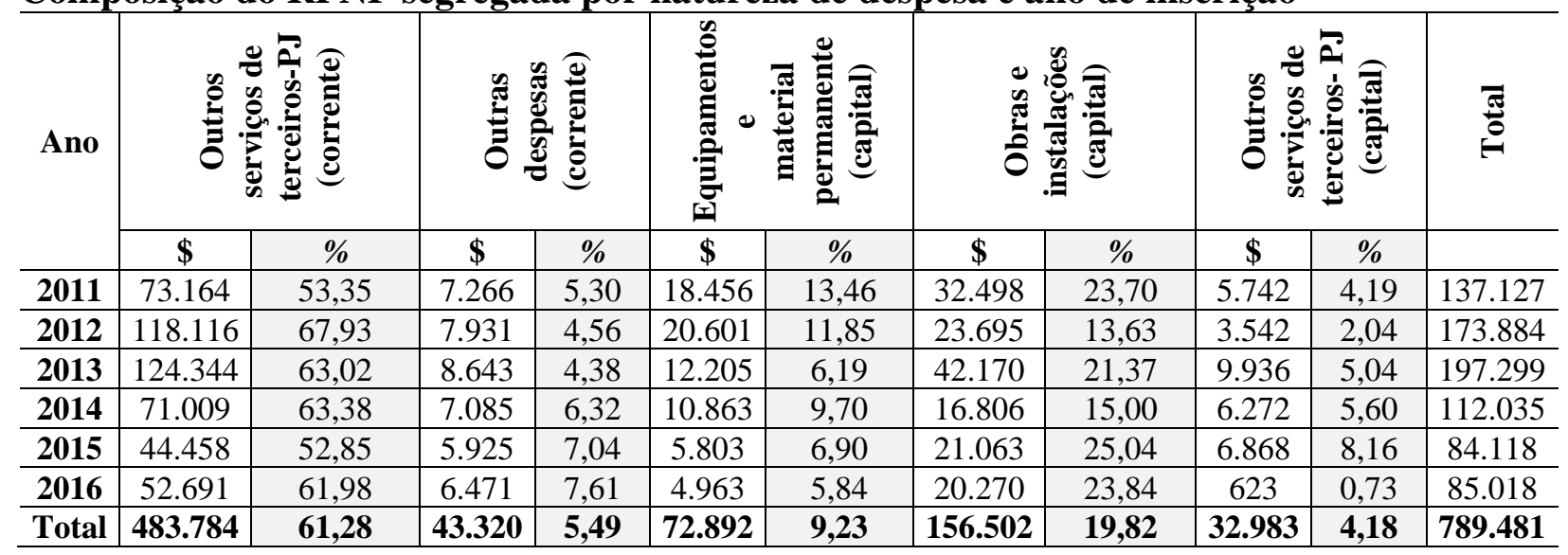

Fonte: Dados da pesquisa (2018).

A Tabela 3 faz uso das categorias econômicas para classificação das despesas, segregandoas, podendo-se classificar as despesas orçamentárias em corrente (categoria econômica 3) e de capital (categoria econômica 4). As correntes podem ser entendidas como as de custeio da administração pública; já as de capital são aquelas que incorporam valor ao patrimônio público na forma de aquisição ou formação de um bem de capital.

Mediante a pormenorização das despesas que compõe o RPNP, verifica-se que a maior parte desta composição $(66,77 \%)$ corresponde a despesas correntes (categoria econômica 3), sendo formada por serviços de terceiros - pessoa jurídica $(61,84 \%)$. Para fins de melhor apresentação, 16 naturezas de despesas foram agrupadas sob o nome de "Outras Despesas Correntes" e 
representam 5,49\% do total. As despesas de capital (categoria econômica 4) representam 33,23\% do total e tem sua composição formada por 3 naturezas de despesa, sendo elas: obras e instalações $(19,82 \%)$, equipamentos e material permanente $(9,23 \%)$ e outros serviços de terceiros de pessoa jurídica $(4,18 \%)$.

Nota-se, portanto, que as despesas inscritas relativas a natureza de despesa corrente (categoria econômica 3, grupo de natureza de despesa 3), de aplicação direta (modalidade de aplicação 90), especificamente referentes a "outros serviços de terceiros - pessoa jurídica" (elemento de despesa 39), representam uma parcela significativa em cada um dos anos analisados. Nesse elemento de despesa são registradas as decorrentes da prestação de serviços por pessoas jurídicas para órgãos públicos.

A Tabela 4, por sua vez, intenciona elencar a composição desta natureza de despesa por subelementos, com base nas classificações de plano interno da instituição analisada.

Tabela 4

Detalhamento por subelemento das despesas inscritas em Restos a Pagar Não Processados da natureza de despesa "outros serviços de terceiros - pessoa jurídica"

\begin{tabular}{|c|c|c|c|}
\hline Natureza da despesa & Descrição conforme plano interno & Inscrições (R\$) & $\%$ total \\
\hline $\begin{array}{l}33903979 \text { - Serviço de } \\
\text { apoio administrativo, } \\
\text { técnico e operacional }\end{array}$ & $\begin{array}{l}\text { Registra o valor das despesas com serviços de limpeza, } \\
\text { higienização, coleta de lixo, retirada de entulho, } \\
\text { conservação, dedetização e asseio dos órgãos públicos } \\
\text { e lavagem de veículo. (Nos casos em que o contrato } \\
\text { não especifique o quantitativo físico do pessoal a ser } \\
\text { utilizado). }\end{array}$ & 223.512 & $46,20 \%$ \\
\hline $\begin{array}{l}33903965 \text { - Serviços de } \\
\text { apoio ao ensino }\end{array}$ & $\begin{array}{l}\text { Registra o valor das despesas de todos os serviços } \\
\text { utilizados com o objetivo de proporcionar o } \\
\text { desenvolvimento e o aperfeiçoamento do ensino, em } \\
\text { todos os níveis, inclusive pesquisas, experiências e } \\
\text { assemelhados. }\end{array}$ & 162.854 & $33,66 \%$ \\
\hline $\begin{array}{c}339039 \text { - Outros serviços } \\
\text { de terceiros - Pessoa } \\
\text { Jurídica }\end{array}$ & $\begin{array}{c}\text { Um total de } 43 \text { subelementos de despesa foram } \\
\text { agrupados nessa categoria pela sua representatividade } \\
\text { em relação ao total analisado }\end{array}$ & 97.417 & $20,14 \%$ \\
\hline Total & & 483.784 & $100,00 \%$ \\
\hline
\end{tabular}

Fonte: Dados da pesquisa (2018).

A análise das informações contidas na Tabela 2 em conjunto com as Tabelas 3 e 4 permite a interpretação da composição dos valores inscritos em Restos a Pagar da Universidade Federal de Santa Catarina no período de 2011 a 2016, respondendo assim ao objetivo de pesquisa. O RP da UFSC é composto em sua maior parte $(61,28 \%)$ por RPNP referente a Outros Serviços de Terceiros - Pessoa Jurídica, que registra as despesas com energia elétrica, água e esgoto, contratos terceirizados, manutenção de imóveis, telefonia, locação de equipamentos, manutenção de equipamentos, entre outras, compõe esta rubrica e são as principais e essenciais para o funcionamento da UFSC.

Recorrendo aos dados da Tabela 1, analisando horizontalmente a evolução dos restos a pagar no decorrer dos anos, nota-se que o ano de 2014 apresenta uma redução no total de RP inscrito, passando de uma taxa de 51,78\% de inscrição em RP do total de empenhos emitidos para 39,55\%, representando uma queda 12,23 pontos percentuais. Os anos subsequentes registram as menores taxas de inscrição do período analisado, 36\% (2015) e 28,61\% (2016). Os Relatórios de Gestão da UFSC registraram a queda desse percentual e indicam as ações efetuadas que resultaram na queda de inscrições em restos a pagar em cada um dos anos:

- "Em 2014, o Departamento de Contabilidade e Finanças (DCF) realizou um esforço para redução dos restos a pagar junto aos fiscais dos contratos cujos empenhos encontravam-se naquela situação.” (UFSC, 2014, p. 250). 
- "Prosseguindo com o esforço realizado em 2014 para redução dos restos a pagar, o DCF contatou os fiscais dos contratos cujos empenhos encontravam-se sem liquidação." (UFSC, 2015, p. 116).

- "Tal redução se deve ao processo de aprimoramento dos controles relativos aos Restos a Pagar, inclusive com a realização de treinamentos específicos na área para Ordenadores de despesas e seus assessores, e a implementação de procedimento específico de indicação de Restos a Pagar a inscrever ao final do exercício, de acordo com o Decreto 93.872/86." (UFSC, 2016, p. 118).

O impacto das ações efetuadas resultou em queda significativa nas contas mais representativas dos RPNP do período. Por ter presença constante em todos os exercícios financeiros e por possuir a maior representatividade diante do montante total de inscrições, como pode ser observado na Tabela 3 , as despesas referentes a contratos de pessoas jurídicas que prestam os serviços essenciais para a universidade apresentam uma dificuldade de passar pela etapa de liquidação no ano que é empenhada. Contudo, ações específicas implementadas pela gestão, como controles no fluxo de inscrição, acompanhamento da etapa de liquidação e treinamento dos ordenadores de despesas, refletiram em uma redução na conta mais representativa da composição do RP e, por consequência, uma redução no volume de RP inscrito no período.

A Figura 3 apresenta a evolução dos montantes de RP inscritos juntamente com as duas naturezas de despesas mais representativas da composição durante os seis anos delimitados por este estudo para análise.

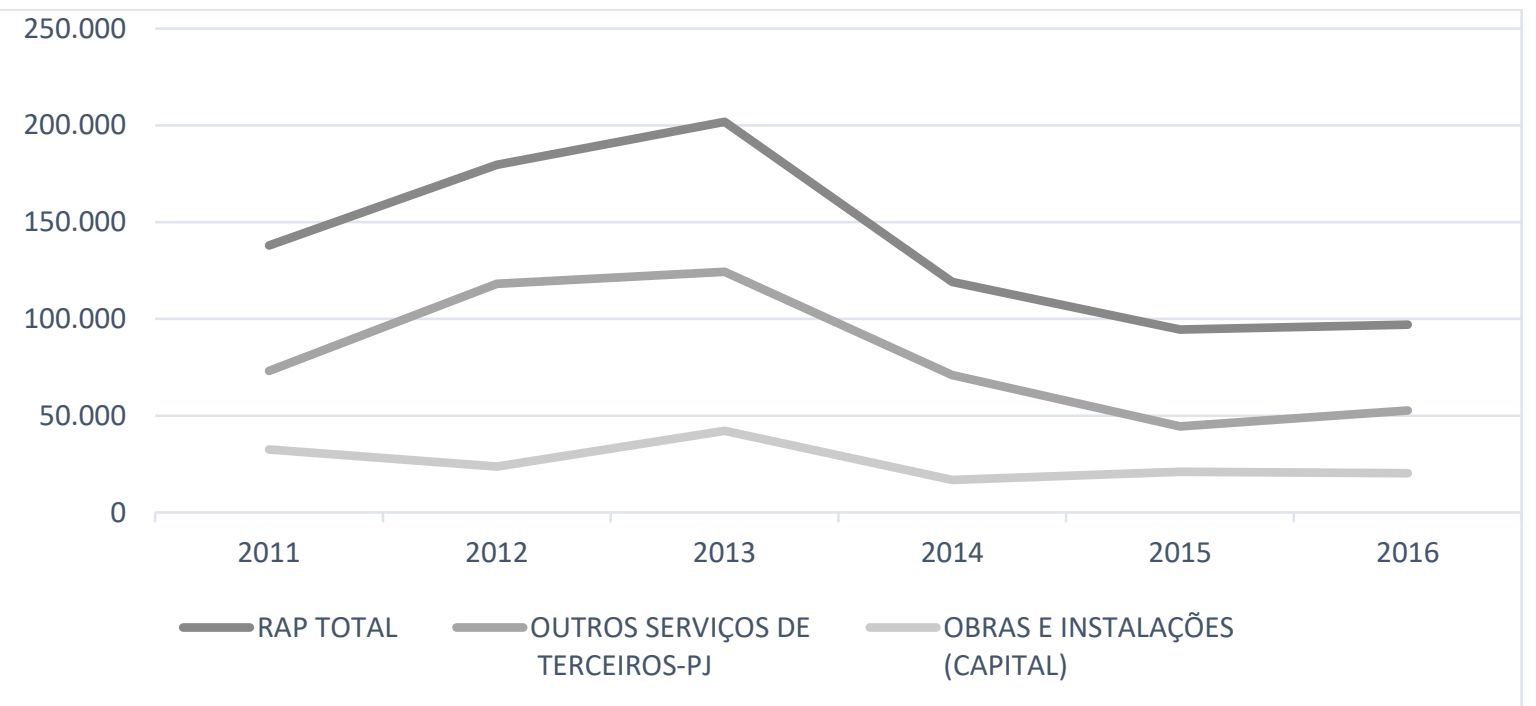

Figura 3. Evolução RP de 2011 a 2016

Fonte: Dados da pesquisa (2018).

Com base nas tabelas e na Figura 3, observa-se o crescimento dos RP até o ano de 2013 e consequente diminuição a partir de 2014.

Além das medidas observadas nos Relatórios de Gestão da entidade a partir de 2014, que demonstram uma ação de gestão no sentido de reduzir o estoque de Restos a Pagar, deve-se também considerar a alteração do Decreto 93.872/86 em 2011, por meio do Decreto 7.654/11, que apesar de trazer um relaxamento em relação ao prazo de validade dos RP, também trouxe a responsabilidade da inscrição dos RPNP para o gestor, deixando de ser automática, conforme apontado por Santana (2016). Desta forma, a própria alteração pode ter relação de causa e efeito no esforço institucional apurado nos Relatórios de Gestão entre 2014 e 2016.

A partir dos achados, salienta-se que eles estão alinhados com os estudos de Neves et al., (2014), Silva et al., (2014) e Santana (2016), nos quais se evidencia que as despesas que mais contribuem para inscrição de restos a pagar são as despesas de capital. As despesas correntes, 
também conhecidas como sendo as despesas de custeio, representam em valores absolutos um montante que corresponde a $80,82 \%$ das inscrições realizadas. Nesta mesma direção, Magalhães et al., (2006) verificaram resultados similares em seu estudo, no qual apontaram como causa o maior prazo concedido pelos fornecedores nas compras efetuadas.

\section{CONSIDERAÇÕES FINAIS}

Este trabalho objetivou verificar o reflexo das ações efetuadas pela Universidade Federal de Santa Catarina na gestão dos restos a pagar no período de 2011 a 2016. Por meio da análise da composição dos restos a pagar, averiguou-se que as despesas de capital apresentam taxas elevadas de inscrição em RP, acima de 70\%, ao analisar o montante total empenhado e inscrito do período.

A segregação do RP em processados e não processados evidenciou que $95,10 \%$ das inscrições realizadas são de despesas cujo empenho foi emitido, contudo, o objeto adquirido ainda não tinha sido entregue, dependendo assim de algum fator para a efetiva liquidação (não processadas). Pormenorizando as despesas que compõe o montante de RPNP do período de 2011 a 2016, observou-se a representatividade significativa das despesas decorrentes da prestação de serviços por pessoas jurídicas para órgãos públicos, especificamente despesas essenciais para o funcionamento da universidade, como de apoio administrativo, técnico e operacional, e serviços utilizados com o objetivo de proporcionar o desenvolvimento e o aperfeiçoamento do ensino.

A evolução ano a ano das inscrições em RPNP da natureza de despesa mais representativa na composição, juntamente com a correlação com indicação das ações dos departamentos responsáveis na gestão de restos a pagar, evidenciou que uma maior interação com os fiscais de contrato, o aprimoramento dos controles relativos aos restos a pagar, a realização de treinamentos específicos na área para ordenadores de despesas e a implementação de procedimentos específicos de indicação de restos a pagar culminaram em uma queda na inscrição de RPNP e por conseguinte em RP. Este resultado verificado na pesquisa, portanto, evidencia que o esforço da gestão, verificado nos relatos retirados dos Relatórios de Gestão, foi, de alguma forma, efetivo na redução do estoque de Restos a Pagar.

Os resultados corroboram as constatações de Aquino e Azevedo (2017), estudo no qual os autores ressaltam a necessidade de que a administração pública invista no uso de ferramentas que possibilitem o acompanhamento da execução orçamentária, com o intuito de auxiliar o gestor do orçamento no alcance da melhoria da gestão dos gastos públicos, evitando assim que o orçamento público seja simplesmente uma "peça de ficção".

Espera-se que estudo possibilite, a partir da realidade da UFSC, uma melhor compreensão acerca de como ações ligadas à gestão de restos a pagar podem impactar na redução de inscrição dos mesmos, combatendo assim a perda do princípio da anualidade e a redução da credibilidade e da transparência orçamentárias causadas pela postergação de gastos pela gestão pública brasileira.

Por fim, salienta-se como limitação desta pesquisa a ênfase nos dados de apenas uma instituição, o que não possibilita a generalização de seus achados. Como sugestão para futuras pesquisas, pode-se: (i) ampliar o período analisado para anos anteriores e posteriores e assim conseguir traçar uma linha evolutiva mais abrangente; (ii) aplicar procedimentos estatísticos mais robustos, como Dados em Painel para visualização do comportamento dos dados; e (iii) aplicar em outros órgãos públicos (universidades ou não), para comparar o comportamento do fenômeno estudado.

\section{REFERÊNCIAS}

Alves, D. P. (2011). Carry-over: A flexibilização do princípio da anualidade orçamentária como indutora da qualidade do gasto público e da transparência fiscal. Brasília: ESAF. Monografia premiada com menção honrosa no XVI Prêmio Tesouro Nacional - 2011. 
Economia e Contabilidade do Setor Público. Brasília (DF). Recuperado em 05 junho, 2017, de http://www.tesouro.fazenda.gov.br/documents/10180/137713/Premio2011_Tema_2_M H1.pdf

Aquino, A. C. B. D., \& Azevedo, R. R. (2017). Restos a pagar e a perda da credibilidade orçamentária. Revista de Administração Pública, 51(4), 580-595.

Aquino, A. C. B. de, \& Azevedo, R. R. (2015). O "IR" realismo orçamentário nos municípios brasileiros. Business and Management Review, 5(1), 210-224.

Camargo, A. M. (2015). Casuísmos dos Restos a Pagar: uma Análise Legalista e Doutrinária. Revista de Ciências Gerenciais, 18(27).

Constituição da República Federativa do Brasil. (1988). Brasília, DF, Senado 1998. Recuperado em $05 \quad$ junho, 2017, http://www.planalto.gov.br/ccivil_03/constituicao/ConstituicaoCompilado.htm

Controladoria Geral da União. (2011). Acesso à informação pública: uma introdução à Lei 12.527, de 18 de novembro de 2011. Brasília. Recuperado em 05 junho, 2017, de http://www.cgu.gov.br/acessoainformacao/materiaisinteresse/CartilhaAcessoaInformacao.p df

Decreto $n^{\circ}$ 93.872, de 23 de dezembro de 1986. (1986). Dispõe sobre a unificação dos recursos de caixa do Tesouro Nacional, atualiza e consolida a legislação pertinente e dá outras providências. Recuperado em 05 junho, 2017, de http://www.planalto.gov.br/ccivil_03/decreto/d93872.htm

Garcia Filho, R. C., Melo, E. J. C., Resende, A. L., de Araujo Neto, L. M., \& Marciniuk, F. L. (2016). A evolução dos restos a pagar não processados no período 2003 a 2013 e a correlação com as transferências voluntárias. CAP Accounting and Management-B4, 9.

Giacomoni, J. (2012). Orçamento Público (16a ed.). São Paulo: Atlas.

Gil, A. C. (1999). Métodos e técnicas de pesquisa social (5a ed.). São Paulo: Atlas.

Kohama, H. (2010). Contabilidade pública: teoria e prática (11a ed.). São Paulo: Atlas.

Lei Complementar, $n^{o}$ 101, 4 de maio de 2000. (2000). LRF - Lei de Responsabilidade Fiscal, Brasília, 24 p., maio, 2000.

Lei $n^{\circ} 4320$, de 4 de março de 1964. (1964). Estatui normas gerais de direito financeiro para a elaboração e controle dos orçamentos e balanços da União, dos Estados, dos Municípios e do Distrito Federal.

Lei $n^{o}$ 8.666, de 21 de junho de 1993.(1993). Regulamenta o art. 37, inciso XXI, da Constituição Federal, institui normas para licitações e contratos da Administração Pública e dá outras providências. Diário Oficial da União, Brasília, DF, 22 jun. 1993. Recuperado em 05 junho, 2017, de http://www.planalto.gov.br/ccivil_03/Leis/L8666cons.htm

Lima, D. V., \& Castro, R. G. (2007). Contabilidade pública: integrando União, Estados e Municípios (Siafi e Siafem) (3a ed.). São Paulo: Atlas. 
Magalhães, E. A., Oliveira, T. B. A., Wakim, V. R., \& Faroni, W. (2006). Análise da evolução da despesa orçamentária em uma instituição de ensino superior: o caso da Universidade Federal de Viçosa (UFV). Anais do Congresso Brasileiro de Custos-ABC. Recuperado em 20 dezembro, 2017, de https://anaiscbc.emnuvens.com.br/anais/article/viewFile/1749/1749

MCASP - Manual De Contabilidade Aplicada Ao Setor Público (2017). $7^{\text {a }}$ Edição. Secretaria de Tesouro Nacional. Recuperado em 22 janeiro, 2019, de http://www.tesouro.fazenda.gov.br/documents/10180/456785/CPU_MCASP+6\%C2\%AA \% 20edi\%C3\%A7\%C3\%A3o_Republ2/fa1ee713-2fd3-4f51-8182-a542ce123773/

Ministério do Planejamento, Orçamento e Gestão. (2005). Guia "d" Simplificação. Brasília: MPOG. Recuperado em 05 junho, 2017, de http://www.gespublica.gov.br/sites/default/files/documentos/D.pdf

Neres, D. V. (2010). Restos a pagar: análise dos procedimentos adotados na prefeitura de Biguaçu. Monografia de Ciências Contábeis, Universidade Federal de Santa Catarina, Florianópolis, SC, Brasil. Recuperado em 20 dezembro, 2017, de https://repositorio.ufsc.br/handle/123456789/127036

Neves, T. J. G. D., Libonati, J. J., Miranda, L. C., \& De Menezes, S. M. M. (2014). Um Estudo Qualitativo da Execução Física e Orçamentária dos Programas Orçamentários nas Universidades Federais Brasileiras. Congresso Controladoria e Contabilidade-USP. Novas Perspectivas na Pesquisa Contábil, 14.

Peixoto A. A. A., \& Peixoto A. G. (2017). Restos A Pagar - Um Procedimento Contábil Legalmente Instituído com Severas Implicações no Equilíbrio Orçamentário. Anais do Congresso Internacional de Desempenho no Setor Público, 1.

Piscitelli, R. B., \& Timbó, M. Z. F. (2010). Contabilidade pública: uma abordagem da administração financeira pública (11a ed.). Rev. ampl. e atual. São Paulo: Atlas.

Santana, G. M. (2016). Análise da inscrição e execução dos Restos a Pagar na Universidade Federal de Santa Catarina nos anos de 2011 a 2013. Monografia de Ciências Contábeis, Universidade Federal de Santa Catarina, Florianópolis, SC, Brasil. Recuperado em 20 dezembro, 2017, de https://repositorio.ufsc.br/xmlui/handle/123456789/166683

Secretaria do Tesouro Nacional. (2017). Manual de Contabilidade Aplicada ao Setor Público. Parte Geral, I, II, III, IV e V (7a ed.). Brasília: STN.

Silva, C. E. T. D., Neves, T. J. G. D., Campos, J. D. D. S., \& Vasconcelos, A. L. F. D. S. (2014). Execução orçamentária: um estudo sobre a inscrição de restos a pagar nas universidades federais do Nordeste. Anais do Colóquio Internacional de Gestão Universitária, Florianópolis, SC, Brasil, 14. Recuperado em 20 dezembro, 2017, de https://repositorio.ufsc.br/xmlui/handle/123456789/132042

Slomski, V. (2013). Manual de contabilidade pública: de acordo com as normas internacionais de contabilidade aplicadas ao setor público (IPSASB/IFAC/CFC) (3a ed.). São Paulo: Atlas.

Universidade Federal de Santa Catarina (2014). Relatório de Gestão de 2013. Florianópolis. Recuperado em 28 janeiro, 2017, de http://dpgi.seplan.ufsc.br/relatorio-de-gestao/ 
Universidade Federal de Santa Catarina (2015). Relatório de Gestão de 2014. Florianópolis. Recuperado em 28 janeiro, 2017, de http://dpgi.seplan.ufsc.br/relatorio-de-gestao/

Universidade Federal de Santa Catarina (2016). Relatório de Gestão de 2015. Florianópolis. Recuperado em 28 janeiro, 2017, de http://dpgi.seplan.ufsc.br/relatorio-de-gestao/

Universidade Federal de Santa Catarina (2017). Relatório de Gestão de 2016. Florianópolis. Recuperado em 28 janeiro, 2017, de http://dpgi.seplan.ufsc.br/relatorio-de-gestao/ 